\title{
Elevation Changes
}

Changes in elevation must always be taken into account in calculating a sprinkler system.

All of us(?) have learned somewhere along the way that a cubic foot of water weighs $62.4 \mathrm{lb}$. (Actually, 62.4 is the weight of water at $52.72^{\circ} \mathrm{F}$. It weighs slightly less at higher temperatures, slightly more at lower temperatures. $52.72^{\circ}$, however, is a reasonable temperature).

If you think of a cubic foot as a cube one foot square and one foot high, it should be apparent that when you divide 62.4 by the number of square inches in a square foot, the result is the weight of a one-square-inch column of water one foot high, or the pressure, in pounds per square inch, exerted by one foot of water.

$$
62.4 \div 144=0.433
$$

Thus, the pressure must be increased by 0.433 psi for every foot by which the elevation is reduced and decreased by 0.433 psi for every foot by which the elevation is increased. When all sprinklers assumed to be discharging are at the same elevation, it is recommended that all elevation changes be ignored until you reach the main riser. At the main riser, the pressure should be increased to reflect the total difference in elevation between the base of the riser (see definition on page 102) and the sprinklers assumed to be operating.

When the sprinklers assumed to be discharging are at different elevations (a pitched roof is a common example - see pages 97 through 100), it is necessary to adjust the pressure for elevation at each step in the assumed discharge area because the pressure change due to elevation will affect the actual discharge. Again, however, all elevation changes not affecting a discharging sprinkler are best ignored until the calculations reach the main riser. It is simpler to account for all elevation changes at one time and, when branch-line $k$ 's are used, unnecessary errors are avoided (see page 185). 